\title{
Study of Photocatalytic Degradation of Methyl Orange on Different Morphologies of ZnO Catalysts
}

\author{
Chih-Wei Tang \\ Department of General Education, Army Academy, Taoyuan, Chinese Taipei \\ Email: cwtang5905@gmail.com, cwtang@aaroc.edu.tw
}

Received January 2, 2013; revised February 6, 2013; accepted February 16, 2013

Copyright (C) 2013 Chih-Wei Tang. This is an open access article distributed under the Creative Commons Attribution License, which permits unrestricted use, distribution, and reproduction in any medium, provided the original work is properly cited.

\begin{abstract}
In this study, several $\mathrm{ZnO}$ catalysts were prepared using different zinc sources as precursors. The different catalyst morphologies obtained were used to degrade photocatalytically a methyl orange (MO) dye solution, which was used to model wastewater pollution. The precursors, $\mathrm{Zn}\left(\mathrm{CH}_{3} \mathrm{COO}\right)_{2}, \mathrm{ZnCl}_{2}$ and $\mathrm{Zn}\left(\mathrm{NO}_{3}\right)_{2}$, were individually added to a solution containing cetyltrimethylammonium bromide $(\mathrm{CTAB})$ and sodium hydroxide $(\mathrm{NaOH})$ for the hydrothermal synthesis of $\mathrm{ZnO}$. After the hydrothermal reaction, the samples of $\mathrm{ZnO}$ were filtered, washed, dried at $110^{\circ} \mathrm{C}$ and calcined at $550^{\circ} \mathrm{C}$, resulting in the formation of the rod-like (designated $\mathrm{ZnO}(\mathrm{I})$ ), the rice-like (designated $\mathrm{ZnO}(\mathrm{II})$ ) and the granular-like (designated $\mathrm{ZnO}(\mathrm{III})$ ) catalysts. The catalysts were characterized by X-ray diffraction (XRD), field-emission scanning electron microscope (FE-SEM) and their UV-visible diffuse reflectance spectra (UV-Vis DRS). The results indicate that the photocatalytic degradation of the MO solution, after $60 \mathrm{~min}$ of UV irradiation, can reach percentages of $40 \%, 96 \%$ and $99 \%$ using the catalysts $\mathrm{ZnO}(\mathrm{I}), \mathrm{ZnO}(\mathrm{II})$ and $\mathrm{ZnO}(\mathrm{III})$, respectively. The morphology of the $\mathrm{ZnO}$ catalyst had an apparent effect on the rate of the photocatalytic degradation of $\mathrm{MO}$. The $\mathrm{ZnO}(\mathrm{II})$ and $\mathrm{ZnO}$ (III) catalysts have higher $\mathrm{S} / \mathrm{V}$ ratios and a greater content of oxygen vacancies, resulting in different absorbances of ultraviolet light, which leads to different rates of photocatalytic degradation of MO.
\end{abstract}

Keywords: $\mathrm{ZnO}$; Morphology; Hydrothermal; Rod-Like; Rice-Like; Granular-Like

\section{Introduction}

Within the last decade, green chemistry has been recognized as a potential approach toward scientifically based environmental protection. Recently, photocatalysis has come to be considered one of the most important, environmentally friendly, clean chemical technologies for green chemistry [1]. In the environment, wastewater containing various organic dyes has become one of the major industrial pollutants. Photocatalytic oxidation has increasingly demonstrated its superiority in the decomposition of pollutants that are both highly toxic and difficult to treat by general chemical techniques. Photocatalysis is a potential technology for the decomposition of organic pollutants in wastewater, such as benzene and its derivatives, which poses a significant present or potential hazard to human health and safety and to the environment $[2,3]$.

Photocatalytic processes involving the oxidation of organic compounds in wastewater are achieved by the reactive hydroxyl radical. As one of the proven semiconductor photocatalysts, zinc oxide $(\mathrm{ZnO})$ has been widely used as a photocatalyst, due to its high activity, low cost and environmentally friendly properties [4-6]. $\mathrm{ZnO}$ has received considerable attention in the photocatalytic degradation of environmental pollutants because its direct band gap $(3.37 \mathrm{eV})$ is larger than that of $\mathrm{TiO}_{2}[7]$ and because $\mathrm{ZnO}$ exhibits high efficiency in the photodegradation of certain organic dyes, such as thionine, methylene blue, acridine orange, benzene and its derivatives [8-12]. Although there are many synthetic routes toward $\mathrm{ZnO}$, the hydrothermal method is the most attractive, due to its perfect control of morphology, composition, purity, crystallinity and low cost for large-scale production. Therefore, various precursors have been used to synthesize various $\mathrm{ZnO}$ nanostructures. The ability to grow different nanostructures of $\mathrm{ZnO}$ with well-controlled crystalline morphology is still needed to study the photocatalytic degradation of organic pollutants in wastewater systematically [13-17].

In this paper, the rod-like, rice-like and granular-like $\mathrm{ZnO}$ nanostructures were prepared using different zinc precursors in the hydrothermal synthesis. To investigate the photocatalytic activities; SEM, XRD and UV-vis measurements were undertaken to determine the degradation 
of $\mathrm{MO}$ on these $\mathrm{ZnO}$ catalysts. Methyl orange (MO) was selected as a target pollutant, due to its solubility in water, which is a requirement for chemicals present in wastewater from industrial emissions.

\section{Experimental}

\subsection{Preparations of Catalysts}

Different morphologies of $\mathrm{ZnO}$ catalysts were prepared using a hydrothermal reaction under basic conditions using the surfactant cetyltrimethylammonium bromide (CTAB, $\mathrm{C}_{19} \mathrm{H}_{42} \mathrm{NBr}$ ) and different sources of zinc.

In a typical experiment for the 1) rod-like $\mathrm{ZnO}$ catalyst, $1.46 \mathrm{~g}$ of zinc nitrate $\left(\mathrm{Zn}\left(\mathrm{NO}_{3}\right)_{2} \cdot 6 \mathrm{H}_{2} \mathrm{O}\right), 1.0 \mathrm{~g}$ of CTAB and $3.0 \mathrm{~g}$ of $\mathrm{NaOH}$ were dissolved in $45 \mathrm{~mL}$ of deionized water and stirred for $1 \mathrm{~h}$, and the solution was added into a $100 \mathrm{~mL}$ Teflon-lined stainless steel reaction vessel. The molar ratio of $\mathrm{CTAB} /$ zinc nitrate was 1:2.26. The vessel was sealed and maintained at $160^{\circ} \mathrm{C}$ in an oven for $24 \mathrm{hrs}$. 2) Rice-like $\mathrm{ZnO}$ catalyst: $2.5 \mathrm{~g}$ of zinc acetate $\left(\mathrm{Zn}\left(\mathrm{CH}_{3} \mathrm{COO}\right)_{2} \cdot 2 \mathrm{H}_{2} \mathrm{O}\right), 1.73 \mathrm{~g}$ of CTAB and $2.0 \mathrm{~g}$ of $\mathrm{NaOH}$ were dissolved in $40 \mathrm{~mL}$ of deionized water and stirred for $1 \mathrm{~h}$, and the solution was added into a $100 \mathrm{~mL}$ Teflon-lined stainless steel reaction vessel. The molar ratio of $\mathrm{CTAB} /$ zinc acetate was $1: 2.38$ [18]. The vessel was sealed and maintained at $160^{\circ} \mathrm{C}$ in an oven for $24 \mathrm{hrs}$. 3) Granular-like $\mathrm{ZnO}$ catalyst: $1.0 \mathrm{~g}$ of zinc chloride $\left(\mathrm{ZnCl}_{2} \cdot 2 \mathrm{H}_{2} \mathrm{O}\right), 1.18 \mathrm{~g} \mathrm{CTAB}$ and $1.36 \mathrm{~g}$ of $\mathrm{NaOH}$ were dissolved in $20 \mathrm{~mL}$ of deionized water and stirred for $1 \mathrm{~h}$, and the solution was added into a $100 \mathrm{~mL}$ Teflon-lined stainless steel reaction vessel. The molar ratio of CTAB/ zinc chloride was 1:2.26. The vessel was sealed and maintained at $140^{\circ} \mathrm{C}$ in an oven for $24 \mathrm{~h}$.

All samples were subsequently allowed to cool to room temperature. The white precipitate was filtered, washed with deionized water and dried in air at $110^{\circ} \mathrm{C}$ for $24 \mathrm{~h}$. The obtained white powders were then calcined at $550^{\circ} \mathrm{C}$ for $4 \mathrm{~h}$. The $\mathrm{ZnO}$ catalysts of rod-like, rice-like and granular-like varieties were designated $\mathrm{ZnO}$ (I), $\mathrm{ZnO}$ (II) and $\mathrm{ZnO}(\mathrm{III})$, respectively, as shown in Table $\mathbf{1}$.

\subsection{Structural and Morphological Analysis}

The crystal structures of the products were characterized by power X-ray diffraction (XRD, Siemens D-5000 diffractometer with $\mathrm{CuK}_{\alpha 1}$ radiation $\left.(\lambda=1.5406 \AA)\right)$ at room temperature. The peak intensities and positions were obtained between $20^{\circ}$ and $80^{\circ}$ with a velocity of 0.02 degrees per second. The morphologies and microstructures of the samples were investigated by FE-SEM using a LEO 1530 scanning electron microscope.

\subsection{Photocatalytic Degradation Experiment}

The photocatalytic activities of the different $\mathrm{ZnO}$ mor-
Table 1. The photocatalytic degradation efficiency of Methyl orange (MO) solutions on $\mathrm{ZnO}$ catalysts obtained from the different morphology by $350 \mathrm{~nm}$ of $\mathrm{UV}$-visible.

\begin{tabular}{cccccc}
\hline \multirow{2}{*}{ Sample $^{\mathrm{a}}$} & Precursor & Morphology & $\mathrm{I}_{\mathrm{Abs}}(\%)$ & \multicolumn{2}{c}{$\mathrm{P}_{\mathrm{d}}$ efficiency $(\%)^{\mathrm{b}}$} \\
\hline $\mathrm{ZnO}(\mathrm{I})$ & $\mathrm{Zn}\left(\mathrm{NO}_{3}\right)_{2}$ & Rod-like & 79 & 24 & 60 mins \\
$\mathrm{ZnO}(\mathrm{II})$ & $\mathrm{Zn}\left(\mathrm{CH}_{3} \mathrm{COO}\right)_{2}$ & Rice-like & 99 & 76 & 96 \\
$\mathrm{ZnO}(\mathrm{III})$ & $\mathrm{ZnCl}_{2}$ & Granular-like & 100 & 78 & 99
\end{tabular}

${ }^{\mathrm{a} A l l}$ samples were prepared by hydrothermal method which were calcined temperature at $550^{\circ} \mathrm{C}$. ${ }^{\mathrm{b}} \mathrm{The}$ photocatalytic degradation efficiencies were calculated using the absorbance $\left(\mathrm{I}_{\mathrm{Abs}}\right)$ at $280 \mathrm{~nm}$ obtained from the DRS spectra of the $\mathrm{ZnO}$ catalysts.

phologies were determined by measuring the degradation of a MO dye solution at room temperature using a Rayonet Photochemical Chamber Reactor containing 16 RPR3500 A lamps. A dye solution was prepared $(10 \mathrm{mg} / \mathrm{L})$ by dissolving the appropriate amount of dye powder in deionized water. Approximately $50 \mathrm{~mL}$ of this solution was placed in the photoreactor followed by the addition of the $\mathrm{ZnO}$ catalyst with a concentration of $1 \mathrm{~g} / \mathrm{L}$, and the mixture was stirred slowly in darkness for $1 \mathrm{~h}$ to eliminate pre-produced electrons and holes from environmental light sources [19]. The dye solution containing the $\mathrm{ZnO}$ catalyst was subsequently illuminated, and samples were taken out at different time points within a $60-\mathrm{min}$ reaction. After separating the sample from the dye solution by centrifuge, the dye concentration was determined by its UV absorption spectra using a Hitachi U-3310 spectrometer. The maximum absorption wavelength of the $\mathrm{MO}$ (chemical formula: $\mathrm{C}_{14} \mathrm{H}_{14} \mathrm{~N}_{3} \mathrm{NaO}_{3} \mathrm{~S}, \lambda_{\max }=464 \mathrm{~nm}$ ) was recorded. The decomposition efficiency of $\mathrm{MO}$ was calculated using the following: the $\mathrm{MO}$ decomposition efficiency $(\%)=\left(\mathrm{C}_{\mathrm{o}}-\left(\mathrm{C} / \mathrm{C}_{\mathrm{o}}\right)\right) \times 100$, where $\mathrm{C}_{\mathrm{o}}$ and $\mathrm{C}$ are the equilibrium concentration in the aqueous solution, which is below $10 \mathrm{mg} / \mathrm{L}$ and is linearly proportional to the intensity of the measured peak.

\section{Results and Discussion}

\subsection{Characterization of Different Morphology ZnO Catalysts}

Figures 1(a)-(c) show the SEM images of the different catalyst morphologies, which depend on the zinc precursor. Figure 1(a) shows the semicircular ends of the rodlike $\mathrm{ZnO}$ catalyst, and the lengths and widths were measured to be in the range of $1.0-7.0 \mu \mathrm{m}$ and $100-200 \mathrm{~nm}$, respectively.

Figure 1(b) shows the rice-like $\mathrm{ZnO}$ catalyst obtained with lengths in the range of $250-1000 \mathrm{~nm}$. In Figure 1(c), the size of the granular-like $\mathrm{ZnO}$ catalyst was measured to be $50-150 \mathrm{~nm}$. Comparison of the SEM images of the different morphological $\mathrm{ZnO}$ catalysts revealed 

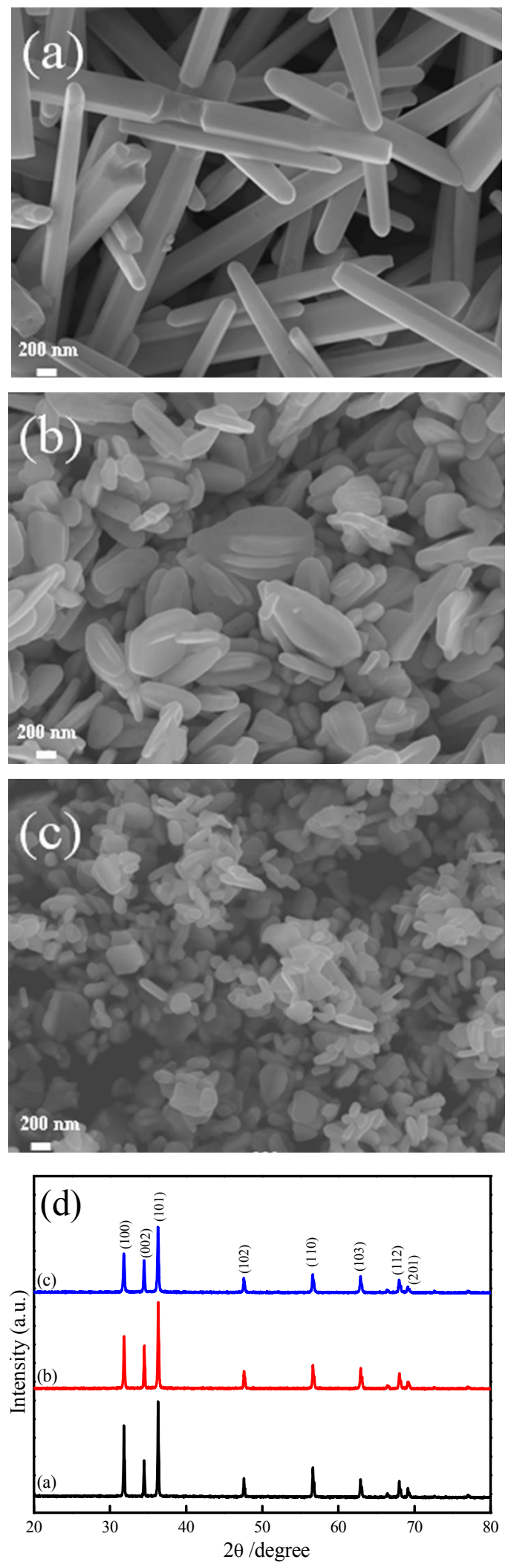

Figure 1. FE-SEM images of the rod-like (a) The rice-like; (b) And the granular-like; (c) ZnO catalysts; and XRD patterns; (d) Of the different morphological $\mathrm{ZnO}$ catalysts are presented. that they could maintain their shape, even after they were calcined at $550^{\circ} \mathrm{C}$. Figure 1(d) shows the XRD patterns of the different morphologies grown using zinc nitrate, zinc acetate and zinc chloride as the $\mathrm{ZnO}$ precursor. Several well-defined diffraction reflections characteristic of $\mathrm{ZnO}$ were observed in the obtained X-ray diffraction patterns (Figure 1(d)). These reflections appeared at $31.6^{\circ}$, $34.4^{\circ}, 36.1^{\circ}, 47.6^{\circ}, 56.7^{\circ}, 62.9^{\circ}, 68.0^{\circ}$ and $69.2^{\circ}$ correspond to the lattice planes of (100), (002), (101), (102), (110), (103), (112) and (201), respectively. The observed diffraction peaks can be indexed to the hexagonal wurtzite structure of $\mathrm{ZnO}$ (JCPDS 36-1451). No other diffraction peaks were detected, which indicates that there were no impurities present and that the precursors had been completely transformed into $\mathrm{ZnO}$. According to these results, it is apparent that different morphologies of $\mathrm{ZnO}$ can be obtained using different zinc precursors and by controlling the reaction temperature and time.

\subsection{UV-Vis Diffuse Reflectance Analysis}

The UV-vis diffuse reflectance spectra of the different morphological $\mathrm{ZnO}$ catalysts are shown in Figure 2. It was found that the absorbance of the $\mathrm{ZnO}$ begins to decrease at $380 \mathrm{~nm}$, while the band-edge of the rod-like $\mathrm{ZnO}$ catalyst was slightly shifted to shorter wavelengths of $7 \mathrm{~nm}$, and a decrease in absorbance (79\%) was observed compared to the rice-like and granular-like $\mathrm{ZnO}$ catalysts $(100 \%)$. The blue shift of the band edge has been previously observed in the rod-like $\mathrm{ZnO}$ [20].

For a direct band gap semiconductor, the relationship between the absorption edge and the photon energy $(h v)$ can be written as follows:

$$
(\alpha h v)^{2}=A\left(h v-E_{g}\right)
$$

where $A$ is the absorption constant that depends on the material of the direct band gap semiconductor. The absorption coefficient $(\alpha)$ is determined from the scattering

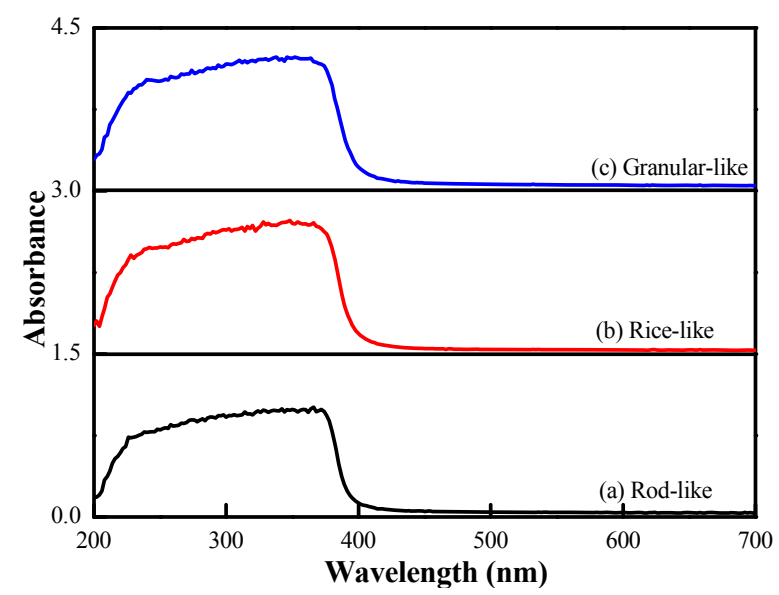

Figure 2. UV-vis DRS spectra of rod-like (a) Rice-like; (b) And granular-like; (c) $\mathrm{ZnO}$ catalysts. 
and reflectance spectra according to the Kubelka-Munk theory $[20,21]$. The s-d and p-d exchange interactions lead to a negative and a positive correction factor in the conduction band and valence band edges, respectively, thereby resulting in band gap narrowing [22].

\subsection{Photocatalytic Degradation of Methyl Orange}

The time-dependent UV-Vis spectra of the MO solution during irradiation are illustrated in Figures 3(a)-(c).

For the rod-like $\mathrm{ZnO}$ catalyst, it can be observed that the maximum absorbance at $464 \mathrm{~nm}$ had degraded by $24 \%$ after irradiation for $30 \mathrm{~min}$, when after $60 \mathrm{~min}$ of irradiation, the peak degraded by $40 \%$, Figure 3(a). After $30 \mathrm{~min}$ of $\mathrm{MO}$ degradation on the rice-like and the granular-like $\mathrm{ZnO}$ catalysts, the peaks had degraded by $76 \%$ and $78 \%$, respectively. However, after irradiation for $60 \mathrm{~min}$, the rice-like and granular-like $\mathrm{ZnO}$ catalysts nearly caused the peak to disappear, achieving $96 \%$ and $99 \%$ MO degradation, respectively, as shown in the $6^{\text {th }}$ column of Table 1.

In addition to the experiments with $\mathrm{ZnO}$ and irradiation, both blank experiments were investigated, which included the absence of irradiation with $\mathrm{ZnO}$, or the presence of irradiation without $\mathrm{ZnO}$. While in the presence of irradiation and $\mathrm{ZnO}, \mathrm{MO}$ can easily be photocatalytically degraded, and Figure 3(d) shows the degradation efficiency of $\mathrm{MO}$ over the various morphological $\mathrm{ZnO}$ catalysts. Blank experiments performed without the $\mathrm{ZnO}$ catalyst under identical UV irradiation for $60 \mathrm{~min}$ showed that none of the MO in solution had been degraded (symbol $\nabla$ of curve). After UV irradiation for $60 \mathrm{~min}$, approximately $40 \%$ (symbol of curve) of the MO is degraded over the rod-like $\mathrm{ZnO}$ catalyst (Figure 3(a)). The ricelike (Figure 3(b)) and granular-like (Figure 3(c)) $\mathrm{ZnO}$ catalysts show that $96 \%$ (symbol $O$ of curve) and $99 \%$ (symbol $\diamond$ of curve) of the MO in solution is decomposed after 60 min of UV irradiation. In general, the photocatalytic activity of a catalyst in the degradation of pollutants is related to its bands gap energy and is due to the nanosized structures and high surface areas [22,23].

In our study, it is easy to understand that the effective surface area of the granular-like $\mathrm{ZnO}$ and the rice-like $\mathrm{ZnO}$ nanostructures is larger than that of the rod-like $\mathrm{ZnO}$. Thus, the high photocatalytic activity of the granular-like $\mathrm{ZnO}$ and the rice-like $\mathrm{ZnO}$ nanostructures can be ascribed to their small size and leads to an increase in both the band gap energy and its surface-to-volume (S/V) ratio [24].

Additionally, the granular-like and rice-like nanostructures favor the movement or transfer of electrons and holes generated inside the crystal to the surface [25], which helps to enhance the photocatalytic activity of the granular-like $\mathrm{ZnO}$ catalyst to a certain degree. According to the mechanism of semiconductor photocatalysis, the

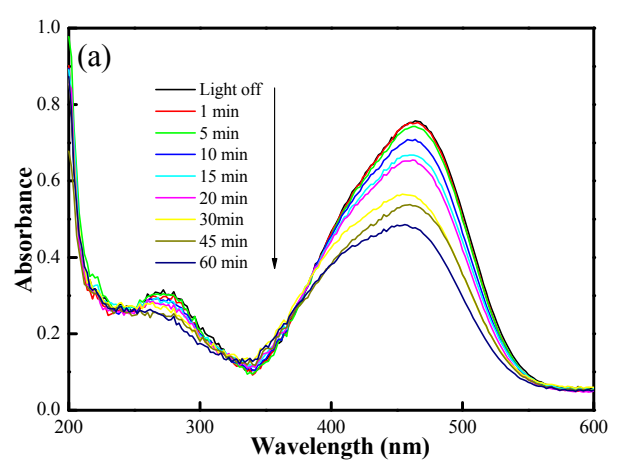

(a)

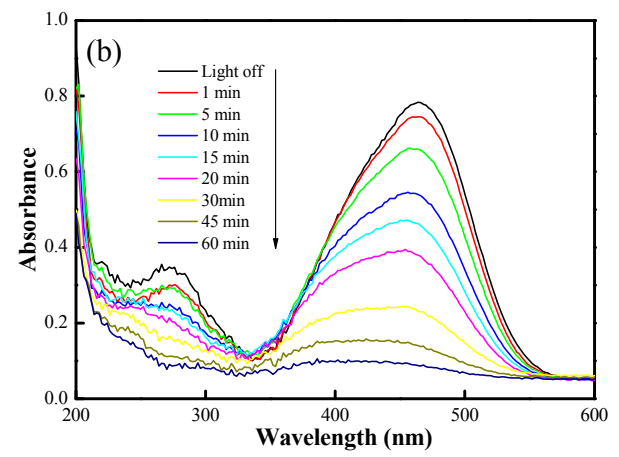

(b)

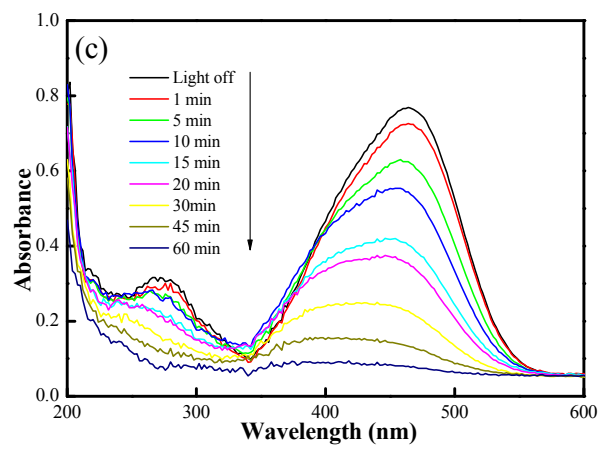

(c)

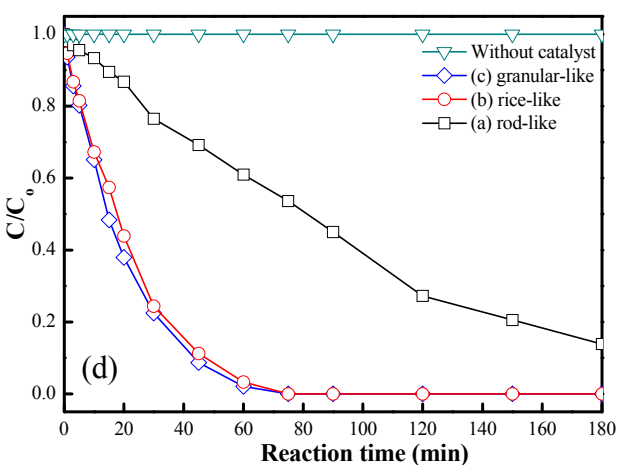

(d)

Figure 3. UV-vis adsorption spectra of MO after different irradiation times using rod-like (a) Rice-like; (b) granularlike; (c) $\mathrm{ZnO}$ as a photocatalyst; and (d) MO degradation versus reaction time for different morphologies of the $\mathrm{ZnO}$ catalyst. 
irradiation of a photocatalyst particle with supra-band-gap energy results in the formation of photogenerated electron-hole pairs. These pairs subsequently diffuse to the surface, where the electrons are captured by an oxygen molecule and the hole by an adsorbed hydroxide, which later forms a hydroxyl radical. Before the electrons and holes reach the surface, there is a significant chance of recombination.

However, semiconductor nanocrystallites exhibit interesting photocatalytic properties and particle sizes at the nanometer scale, resulting in quantum size effects at dimensions comparable to that of the Bohr diameter of the exciton [26]. In the present experiment, using different precursors, different sizes and morphologies of $\mathrm{ZnO}$ were prepared, including the rod-like and rice-like morphologies (nano-sized) and the granular-like morphology (microsized), which were obtained after individual calcination at $550^{\circ} \mathrm{C}$. Thus, the nano-sized morphology of the ricelike and granular-like $\mathrm{ZnO}$ catalysts result in a good quantum size effect; therefore, these catalysts exhibit high photocatalytic efficiencies [27].

\section{Conclusion}

Different morphologies of $\mathrm{ZnO}$ catalysts were prepared and include the rod-like, rice-like and granular-like varieties, and their photocatalytic efficiencies were investigated by the degradation of a methyl orange dye solution. The results show that the different precursors have completely distinct surface morphologies. The rod-like $\mathrm{ZnO}$ catalyst, with a hexagonal wurtzite structure, was grown using zinc nitrate as a precursor, and the rice-like $\mathrm{ZnO}$ catalyst structure was achieved using zinc acetate, whereas the granular-like catalyst was formed using zinc chloride as the precursor. Moreover, the granular-like and ricelike $\mathrm{ZnO}$ catalysts exhibited outstanding photocatalytic activity, which is primarily due to their high $\mathrm{S} / \mathrm{V}$ ratio and higher content of oxygen vacancies. This investigation may provide guidance for the morphology-controlled synthesis of $\mathrm{ZnO}$ nanostructures and their application in the treatment of organic pollutants.

\section{Acknowledgements}

The author would like to thank the National Science Council, and the short-term domestic visiting scholars to Academia Sinica program for financially supporting this research. Furthermore, the author would like to thank Professor Shu-Hua Chien and Ph.D. Kuan-Chun Huang of the Institute of Chemistry, Academia Sinica for providing supporting equipment and materials.

\section{REFERENCES}

[1] P. T. Anastas, L. B. Bartlett, M. M. Kirchhoff and T. C.
Williamson, "The Role of Catalysis in the Design, Development, and Implementation of Green Chemistry," Catalysis Today, Vol. 55, No. 1-2, 2000, pp. 11-22.

[2] G. Centi and S. Perathoner, "Catalysis and Sustainable (Green) Chemistry," Catalysis Today, Vol. 77, No. 4, 2003, pp. 287-297.

[3] G. J. Hutchings, "A Golden Future for Green Chemistry," Catalysis Today, Vol. 122, No. 3-4, 2007, pp. 196-200. doi:10.1016/j.cattod.2007.01.018

[4] L. Wang, X. Yang, X. Zhao,Y. Han, R. Zhang and Y. Yang, "Synthesis and Recycle of ZnO Particles for Degradation of Methyl Orange Aqueous Solution," Applied Mechanics and Materials, Vol. 121-126, No. 12, 2012, pp. 587-591. doi:10.4028/www.scientific.net/AMM.121-126.587

[5] S. Chakrabarti and B. K. Dutta, "Photocatalytic Degradation of Model Textile Dyes in Wastewater Using ZnO as Semiconductor Catalyst," Journal of Hazardous Materials, Vol. B112, No. 3, 2004, pp. 269-278. doi:10.1016/j.jhazmat.2004.05.013

[6] C. Hariharan, "Photocatalytic Degradation of Organic Contaminants in Water by ZnO Nanoparticles: Revisited," Applied Catalysis A: General, Vol. 304, No. 8, 2006, pp. 55-61. doi:10.1016/j.apcata.2006.02.020

[7] S. Sakthivel, B. Neppolian, M. V. Shankar, B. Arabindoo, M. Palanichamy and V. Murugesan, "Solar Photocatalytic Degradation of Azo Dye: Comparison of Photocatalytic Efficiency of $\mathrm{ZnO}$ and $\mathrm{TiO}_{2}$," Solar Energy Materials and Solar Cells, Vol. 77, No. 1, 2003, pp. 65-82.

[8] S. Anandan, A. Vinu, T. Mori, N. Gokulakrishnan, P. Srinivasu, V. Murugesan and K. Ariga, "Photocatalytic Degradation of 2,4,6-Trichlorophenol Using Lanthanum Doped $\mathrm{ZnO}$ in Aqueous Suspension," Catalysis Communications, Vol. 8, No. 9, 2007, pp. 1377-1382. doi:10.1016/j.catcom.2006.12.001

[9] H. Fan, X. Zhao, J. Yang, X. Shan, L. Yang, Y. Zhang, X. $\mathrm{Li}$ and M. Gao, "ZnO-Graphene Composite for Photocatalytic Degradation of Methylene Blue Dye," Catalysis Communications, Vol. 29, No. 8, 2012, pp. 29-34.

[10] B. Pare, S. B. Jonnalagadda, H. Tomar, P. Singh and V. W. Bhagwat, "ZnO Assisted Photocatalytic Degradation of Acridine Orange in Aqueous Solution Using Visible Irradiation," Desalination, Vol. 232, No. 1-3, 2008, pp. 8090. doi:10.1016/j.desal.2008.01.007

[11] R. Y. Hong, J. H. Li, L. L. Chen, D. Q. Liu, H. Z. Li, Y. Zheng and J. Ding, "Synthesis, Surface Modification and Photocatalytic Property of ZnO Nanoparticles," Powder Technology, Vol. 199, No. 3, 2009, pp. 426-432. doi:10.1016/j.powtec.2008.07.004

[12] S. A. Khayyat, M. S. Akhtar and A. Umar, "ZnO Nanocapsules for Photocatalytic Degradation of Thionine," Materials Letters, Vol. 81, No. 68, 2012, pp. 239-241. doi:10.1016/j.matlet.2012.04.039

[13] N. Yu, B. Dong, W. W. Yu, B. Hu, Y. Zhang and Yan Cong, "Investigations of $\mathrm{ZnO}$ Nanostructures Grown on Patterned Sapphire Using Different Precursors in Aqueous Solutions," Applied Surface Science, Vol. 258, No. 15, 2012, pp. 5729-5732. doi:10.1016/j.apsusc.2012.02.078

[14] C. Chena, B. Yu, P. Liu, J. F. Liu and L. Wang, "Investi- 
gation of Nano-Sized ZnO Particles Fabricated by Various Synthesis Routes," Journal of Ceramic Processing Research, Vol. 12, No. 4, 2011, pp. 420-425.

[15] C. Chen, J. Liu, P. Liu and B. Yu, "Investigation of Photocatalytic Degradation of Methyl Orange by Using Nano-Sized ZnO Catalysts," Advances in Chemical Engineering and Science, Vol. 1, No. 1, 2011, pp. 9-14. doi:10.4236/aces.2011.11002

[16] X. Fang, S. Li, X. H. Wang, F. Fang, X. Y. Chu, Z. P. Wei, J. H. Li, X. Y. Chen and F. Wang, "The Growth and Photocatalytic Property of ZnO Nanofibers Synthesized by Atom Layer Deposition Using PVP Nanofibers as Templates," Applied Surface Science, Vol. 263, No. 4, 2012, pp. 14-17. doi:10.1016/j.apsusc.2012.08.048

[17] F. Z. Sun, X. L. Qiao, F. T. Tan, W. Wang and X. L. Qiu, "Fabrication and Photocatalytic Activities of $\mathrm{ZnO}$ Arrays with Different Nanostructures," Applied Surface Science, Vol. 263, No. 112, 2012, pp. 704-711. doi:10.1016/j.apsusc.2012.09.144

[18] J. B. Zhong, J. Z. Li, Z. H. Xiao, W. Hu, X. B. Zhou, X. and W. Zheng, "Improved Photocatalytic Performance of ZnO Prepared by Sol-Gel Method with the Assistance of CTAB," Materials Letters, Vol. 91, No. 83, 2013, pp. 301303.

[19] M. Farbod and E. Jafarpoor, "Fabrication of Different $\mathrm{ZnO}$ Nanostructures and Investigation of Morphology Dependence of Their Photocatalytic Properties," Materials Letters, Vol. 85, No. 15, 2012, pp. 47-49.

[20] S. T. Tan, B. J. Chen, X. W. Sun, W. J. Fan, H. S. Kwok, X. H. Zhang and S. J. Chua, "Blueshift of Optical Band Gap in ZnO Thin Films Grown by Metal-Organic Chemical-Vapor Deposition," Journal of Applied Physics, Vol. 98, No. 1, 2005, Article ID: 013505. doi:10.1063/1.1940137
[21] J. Z. Kong, A. D. Li, H. F. Zhai, Y. P. Gong, H. Li and D. $\mathrm{Wu}$, "Preparation, Characterization of the Ta-Doped $\mathrm{ZnO}$ Nanoparticles and Their Photocatalytic Activity under Visible-Light Illumination," Journal of Solid State Chemistry, Vol. 192, No. 8, 2009, pp. 2061-2067. doi:10.1016/j.jssc.2009.03.022

[22] T. Sun, J. Qiu and C. Liang, "Controllable Fabrication and Photocatalytic Activity of ZnO Nanobelt Arrays," Journal of Physical Chemistry C, Vol. 112, No. 3, 2008, pp. 715-721. doi:10.1021/jp710071f

[23] E. S. Jang, J. H. Won, S. J. Hwang and J. H. Choy, "Fine Tuning of the Face Orientation of $\mathrm{ZnO}$ Crystals to Optimize Their Photocatalytic Activity," Advanced Materials, Vol. 18, No. 24, 2006, pp. 3309-3312. doi:10.1002/adma.200601455

[24] J. L. Yang, S. J. An, W. I. Park, G. C. Yi and W. Choi, "Photocatalysis Using ZnO Thin Films and Nanoneedles Grown by Metal-Organic Chemical Vapor Deposition," Advanced Materials, Vol. 16, No. 18, 2004, pp. 1661-1664. doi:10.1002/adma.200306673

[25] W. W. Wang, Y. J. Zhu and L. X. Yang, “'ZnO-SnO ${ }_{2}$ Hollow Spheres and Hierarchical Nanosheets: Hydrothermal Preparation, Formation Mechanism, and Photocatalytic Properties," Advanced Functional Materials, Vol. 17, No. 1, 2007, pp. 59-64. doi:10.1002/adfm.200600431

[26] H. Gerischer, "Photoelectrochemical Catalysis of the Oxidation of Organic Molecules by Oxygen on Small Semiconductor Particles with $\mathrm{TiO}_{2}$ as an Example," Electrochimica Acta, Vol. 38, No. 1, 1993, pp. 3-9.

[27] M. Zhang, T. An, X. Hu, C. Wang, G. Sheng and J. Fu, Preparation and Photocatalytic Properties of a Nanometer $\mathrm{ZnO}-\mathrm{SnO}_{2}$ Coupled Oxide," Applied Catalysis A, Vol. 260, No. 2, 2004, pp. 215-222. doi:10.1016/j.apcata.2003.10.025 